\title{
The transcription factor CREM drives an inflammatory phenotype of T cells in oligoarticular juvenile idiopathic arthritis
}

\author{
Kim Ohl ${ }^{1}$, Helge Nickel ${ }^{1}$, Halima Moncrieffe ${ }^{2,3}$, Patricia Klemm¹, Anja Scheufen ${ }^{1}$, Dirk Föll", Viktor Wixler ${ }^{5}$, \\ Angela Schippers' ${ }^{1}$, Norbert Wagner ${ }^{1}$, Lucy R. Wedderburn ${ }^{6,7,8}$ and Klaus Tenbrock ${ }^{*}$
}

\begin{abstract}
Background: Inflammatory effector T cells trigger inflammation despite increased numbers of Treg cells in the synovial joint of patients suffering from juvenile idiopathic arthritis (JIA). The CAMP response element (CREM)a is known to play a major role in regulation of T cells in SLE, colitis, and EAE. However, its role in regulation of effector $T$ cells within the inflammatory joint is unknown.

Methods: CREM expression was analyzed in synovial fluid cells from oligoarticular JIA patients by flow cytometry. Peripheral blood mononuclear cells were incubated with synovial fluid and analyzed in the presence and absence of CREM using siRNA experiments for T cell phenotypes. To validate the role of CREM in vivo, ovalbumin-induced T cell dependent arthritis experiments were performed.

Results: CREM is highly expressed in synovial fluid T cells and its expression can be induced by treating healthy control PBMCs with synovial fluid. Specifically, CREM is more abundant in $C D 161^{+}$subsets, than CD161 ${ }^{-}$subsets, of T cells and contributes to cytokine expression by these cells. Finally, development of ovalbumin-induced experimental arthritis is ameliorated in mice with adoptively transferred $\mathrm{CREM}^{-1-} \mathrm{T}$ cells.
\end{abstract}

Conclusion: In conclusion, our study reveals that beyond its role in SLE T cells CREM also drives an inflammatory phenotype of T cells in JIA.

Keywords: CREM, JIA, Effector T cells

\section{Background}

Juvenile idiopathic arthritis (JIA) is the most common inflammatory rheumatic disease in children and is an autoimmune disease of unknown origin. Apart from cells of the innate immune system like neutrophils and monocytes, which trigger inflammation, $\mathrm{T}$ cells play a dominant role in the inflammatory reaction of the joint. Recent investigations indicate an accumulation of highly inflammatory $\mathrm{CD} 4{ }^{+} \mathrm{CD} 161^{+}$cells in the joints [1-3]. Although the functional relevance of CD161 ligation on $\mathrm{T}$ cell function is less clear, CD161 expression is a useful indicator of inflammatory $\mathrm{T}$ cells. They belong to either Th1, Th17 or Th1/Th17, so called non-classical Th1,

\footnotetext{
*Correspondence: ktenbrock@ukaachen.de

1Department of Pediatrics, Medical Faculty, RWTH Aachen, Pauwelsstr. 30,

D-52074 Aachen, Germany

Full list of author information is available at the end of the article
}

cells and their proportions in synovial fluid (SF) correlate positively with parameters of disease activity $[1,4,5]$. The inflammatory potential of these effector $\mathrm{T}$ cells within the joint is controlled by regulatory $\mathrm{T}$ cells (Tregs). The control, however, is inefficient despite the high presence of Tregs in arthritic joints. Tregs typically are not pro-inflammatory, but recent reports showed that some Tregs also may share functional capabilities with conventional $\mathrm{T}$ cells, like production of inflammatory cytokines in the context of autoimmunity or chronic inflammation [6-8]. These Tregs are part of the CD161 population and also enriched in joints of JIA and rheumatoid arthritis (RA) patients $[2,9]$.

The cAMP response element modulator (CREM) $\alpha$ binds to promoters of genes with cAMP response elements (CRE) and regulates transcription via a chromatin-dependent mechanism. Under physiological 
conditions, the production of CREM is tightly regulated and involves the differential use of alternate promoters and splicing processes, resulting in cell- and tissue-specific expression patterns $[10,11]$. Quite interesting is that in $T$ cells of SLE patients CREM $\alpha$ mRNA and protein expression is increased and this significantly alters the expression of various $\mathrm{T}$ lymphocyte-specific target genes, including IL-2 and IL-17 family cytokines [12-15]. Notably, the observed effects of CREM $\alpha$ on IL-2 and IL-17a cytokine production in humans are also observed in transgenic mice with $\mathrm{T}$ cell-specific CREM $\alpha$ overexpression [16]. These mice have decreased IL-2 and increased IL-17a levels and are more prone to develop signs of autoimmunity (including lymphadenopathy and higher autoantibody titers against double-stranded DNA) when an additional genetic deletion of the $c d 95$ gene (Fas) is present $[16,17]$. Beyond its role in SLE CREM $\alpha$ also contributes to T cell dysregulations in asthma, LPS-induced lung injury, colitis, and EAE [18-21]. Although it is known that T cells contribute to pathogenesis in JIA, the role of CREM here has not been addressed so far.The aim of this study was to evaluate the role CREM expressing T cells in oligoarticular JIA. Our findings indicate that beyond its role in SLE CREM $\alpha$ also contributes to $\mathrm{T}$ cell pathophysiology in oligoarticular JIA by modulating inflammatory and regulatory $\mathrm{T}$ cells.

\section{Methods}

\section{Flow cytometry}

For surface staining, single cell suspensions were stained with anti-CD3 (UCHT1), anti-CD4 (RPA-T4), anti-CD161 (HP-3G10) antibodies (all from eBioscience, Germany). To analyze Foxp3 and CREM expression, cells were fixed and permeabilized with a FOXP3 staining buffer set (eBioscience, Germany) following the manufacturer's instructions and stained with anti-Foxp3 (PCH101) antibodies (eBioscience, Germany), monoclonal anti-CREM (Abcam, Great Britain) or IgG isotype control antibodies for $30 \mathrm{~min}$. Monoclonal anti-CREM antibodies and IgG isotype control antibodies were labeled with Alexa Fluor Antibody Labeling Kits (Thermo Fisher Scientific, USA) according to manufactures instructions. For measurement of intracellular cytokines, cells were treated with propidium iodide $(\mathrm{P} / \mathrm{I})$ and GolgiPlug (BD Bisciences, Germany) for $5 \mathrm{~h}$ and fixed and permeabilized with FoxP3 staining buffer set (eBioscience, Germany) following the manufacturers' instructions. Intracellular cytokines were stained with anti-IFN- $\gamma$ (4S.B3) APC and anti-IL-17 PE (64DEC17) (both eBioscience, Germany) antibodies.

\section{Patients and healthy donors}

All patients were diagnosed as having oligoarticular JIA and were receiving nonsteroidal anti-inflammatory drugs before therapeutic aspiration of SF and administration of corticosteroids. JIA patients were diagnosed according to internationally agreed criteria.Cells were pelleted by centrifugation and supernatants were individually stored at $-20{ }^{\circ} \mathrm{C}$, with this more than twenty different SFs and $\mathrm{HC}$ sera were collected and are included in different experiment in this study. Ethical approval for all experiments was obtained from the local ethics committee. All patients provided fully informed consent or age-appropriate assent where applicable. Sera from healthy controls $(\mathrm{HC})$ were obtained from peripheral blood. For co-incubation wit HC Sera and SF, cells from healthy donors were isolated from buffy coats provided by the local blood bank, Transfusionsmedizin, UniversitätsklinikumAachen, Germany).

\section{Cell isolation}

Human mononuclear cells from patients with JIA were isolated onto a Ficoll (PAN Biotech, Germany) gradient either from peripheral blood (PB) or synovial fluid (SF). Erythrocytes were lysed and cells were washed twice. Peripheral blood mononuclear cells (PBMC) were isolated from healthy donors by the same procedure.

\section{Cell culture}

PBMCs from healthy donors were incubated with $10 \%$ allogenic SF or serum from allogenic healthy controls (HC) in RPMI (Gibco, Germany) with 10\% FCS (Biochrom, Germany). When indicated, cells were stimulated with plate-bound anti-CD3 and anti-CD28 antibodies (both at $3 \mu \mathrm{g} / \mathrm{ml}$; BD Bioscience, Germany) in individual wells of 96-well round-bottom microtiter plates. To knock-down CREM expression, PBMCs and SFMCs were transfected with $5 \mathrm{nM}$ CREM-specific siRNA or irrelevant control siRNA (Origene, USA) using the Amaxa transfection system (Lonza, Switzerland). After four hours cells were transferred in fresh media and either left unstimulated and analyzed after $24 \mathrm{~h}$ or stimulated and anyalzed as indicated.

\section{RNA isolation, complementary DNA (CDNA) synthesis, and} quantitative real-time polymerase chain reaction (PCR)

Total RNA was extracted from cells using an RNeasy Mini Kit (Qiagen, Germany) and transcribed to cDNA using a First Strand cDNA Synthesis Kit (Thermo Fisher Scintific, USA) according to the manufacturer's instructions. Standard quantitative real-time PCR was carried out on a TaqMan 7900 (Applied Biosystems, USA) using the DNA intercalating dye SYBR Green.

\section{Ovalbumin (OVA)-induced arthritis model}

OVA-induced arthritis was induced in mice, as described previously [22]. Briefly, $2 \times 10^{6}$ OVA-specific $\mathrm{CD} 4^{+} \mathrm{CD} 25^{-}$ $\mathrm{T}$ cells from either wild-type (WT) or $\mathrm{CREM}^{-1-} \mathrm{OT}$-II 
mice were injected intraperitoneally into C57BL/6 $\mathrm{RAG}^{-1}$ - mice. Two independent experiments were performed and overall 6 mice per group were analyzed. One day later recipients were immunized with $100 \mu \mathrm{g}$ cationized OVA (Sigma-Aldrich, Germany) in PBS at the base of the tail. On day 7 mice were rechallenged with $60 \mu \mathrm{g}$ cationized OVA injected intra-articularly into the left knee joint. Knee swelling was assessed using calipers at definite time points as the difference between the right (arthritic) before and after OVA-injection.

\section{Mice}

Experiments were performed withage-matched $\mathrm{RAG}^{-/-}$, WT OT-II and $\mathrm{CREM}^{-/-}$OT-II mice (all C57BL/6). $\mathrm{CREM}^{-1-}$ animals were originally cloned and provided by Prof. G. Schütz (Deutsches Krebsforschungszentrum, Heidelberg, Germany) [23]. CREM ${ }^{-/-}$OT-II mice were generated by crossing $\mathrm{CREM}^{-/-}$mice with OT-II mice. All mice were bred in our animal facility and kept under standardized conditions. The study was approved by the regional government authorities and animal procedures were performed according to German legislation for animal protection.

\section{Histology}

Knee joints from mice were fixed in $4 \%$ neutral buffered formalin solution for $24 \mathrm{~h}$. Afterwards they were placed in an EDTA-decalcifying solution (20\% EDTA) for 20 days, dehydrated, and embedded in paraffin blocks. Sections were cut along a longitudinal axis at $6 \mu \mathrm{m}$ and stained with hematoxylin and eosin. Hematoxylin and eosin stained slides were evaluated and scored blindly for exudates, granulocyte infiltration, hyperplasia, fibroblast proliferation/ mononuclear cell infiltration, periarticular mononuclear cell infiltration (each scoring $0-3$ ), bone/cartilage destruction (scoring 0-4), and an additional score of 1 for visible fibrin deposition and periarticular granulocyte infiltration, resulting in a maximum score of 21 .

\section{Statistical analysis}

All data are presented as mean \pm standard error (SEM). Differences between two groups were evaluated using two-tailed unpaired or paired (if indicated), Student's $\mathrm{t}$-test if data were normally distributed. Otherwise, a non-parametric Mann-Whitney test or Wilcoxon matched-pairs signed rank test were performed. All statistical analysis and subsequent graphics generation were performed using GraphPad Prism version 7.0 (GraphPad Software, USA). A $p$-value $<0.05$ was considered to be statistically significant.

\section{Results}

CREMa is overexpressed in synovial fluid T cells of juvenile arthritis patients

T cells from SLE patients have previously been shown to display enhanced CREM $\alpha$ levels, thus pointing to the relevance of CREM $\alpha$ in human disease. Based on these findings we asked if expression of CREM $\alpha$ is also upregulated during another autoimmune disease in which $\mathrm{T}$ cells are involved in pathogenesis. We therefore investigated expression of CREM $\alpha$ in synovial fluid $T$ cells from JIA patients. As shown in Fig. 1, percentages of $\mathrm{CREM}^{\text {high }}$ cells within $\mathrm{CD}^{+} \mathrm{T}$ cells were indeed more abundant in the synovial fluid of JIA patients than in the peripheral blood of healthy controls (Fig. 1a and b).

\section{Incubation of control PBMCs with synovial fluid upregulates FoxP3 and IL-17 expression and involves upregulation of CREM}

Synovial fluid of JIA patients contains high amounts of $\mathrm{FoxP}^{+}$and $\mathrm{IL}-17^{+}$cells $[24,25]$. Hence, we asked whether SF of JIA patients contains factors responsible for differentiation of these type of immune cells and whether this went along with increased expression of CREM. Thus we mimicked the inflammatory setting in the joint in vitro by incubating PBMCs from healthy controls with $10 \%$ allogenic synovial fluid from individual patients for $24 \mathrm{~h}$. As a control we incubated PBMCs from the same healthy controls with $10 \%$ allogenic serum from individual healthy controls for $24 \mathrm{~h}$. We observed increased percentages of FoxP3 positive cells in particular (Fig. 1c and d) and an increase in FoxP3 mRNA in general (Fig. 1e) when PBMC were incubated in the presence of synovial fluid for $24 \mathrm{~h}$. In addition, when restimulated with $\mathrm{P} / \mathrm{I}$ in the presence of Brefeldin A, percentages of $I L-17^{+} \mathrm{T}$ cells (Fig. If and g) and IL-17 mRNA (Fig. 1h) were also increased in SF-stimulated PBMC. Moreover, incubation with SF also upregulated CREM mRNA expression in PBMC (Fig. 1j) and CREM protein expression specifically in T cells (Fig. 1i). Hence, incubation of control PBMCs with SF not only upregulates FoxP3 and IL17 expression but also CREM expression in $\mathrm{T}$ cells. Therefore, we hypothesize that soluble factors within the synovial fluid induce CREM transcription in SF T cells which leads to enhanced expression of CREM in SF T cells.

SF-induced expression of IFN- - , IL-17, and FoxP3 in T cells can be reversed by CREM knock down with CREM-specific siRNA

We next asked if expression of CREM directly influences activation of $\mathrm{T}$ cells and therefore analyzed $\mathrm{T}$ cell activation in the absence of CREM. We isolated $\mathrm{CD} 4^{+} \mathrm{CD} 25^{-}$ cells from healthy donors, transfected them with CREM-specific siRNA or control siRNA. Flow cytometric 

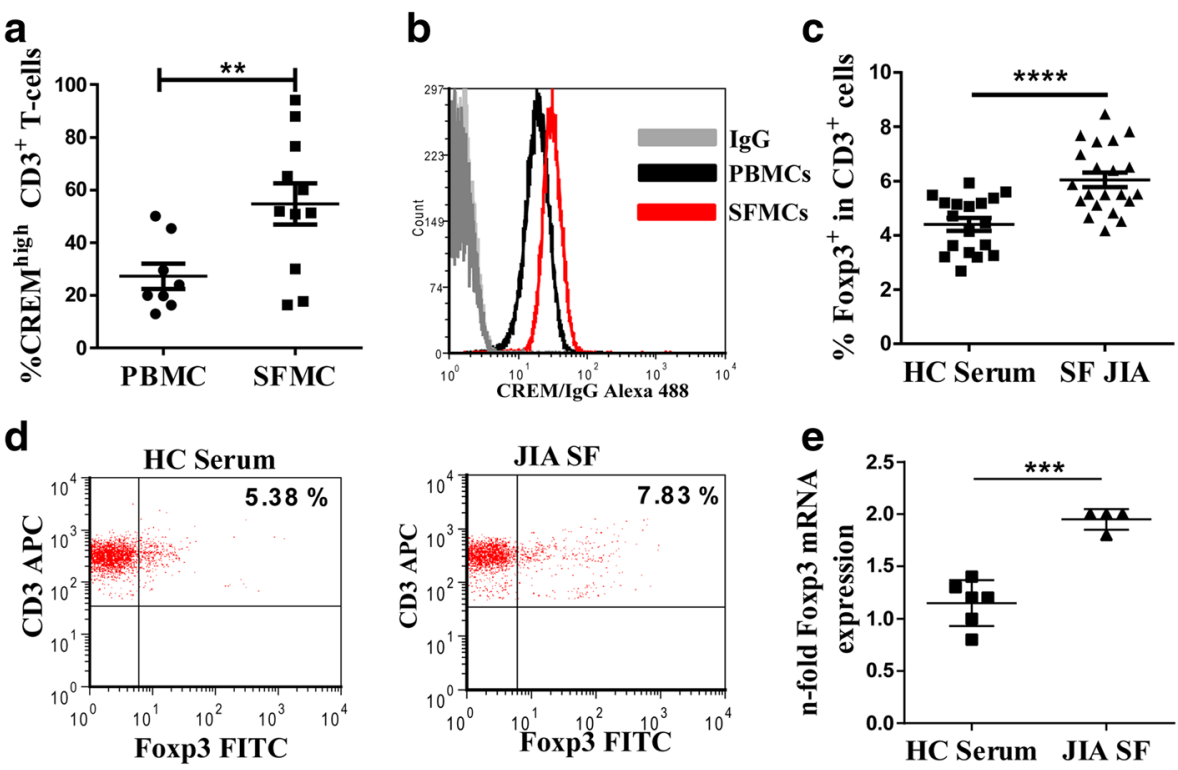

f
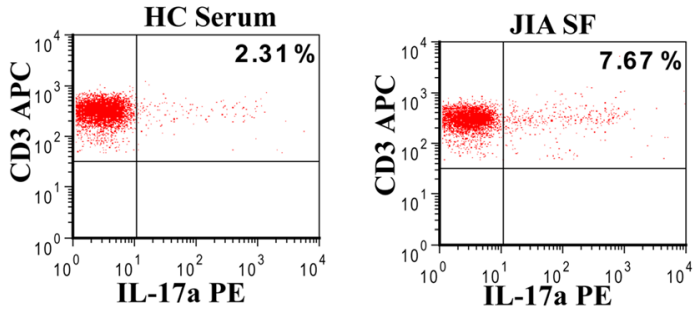

g
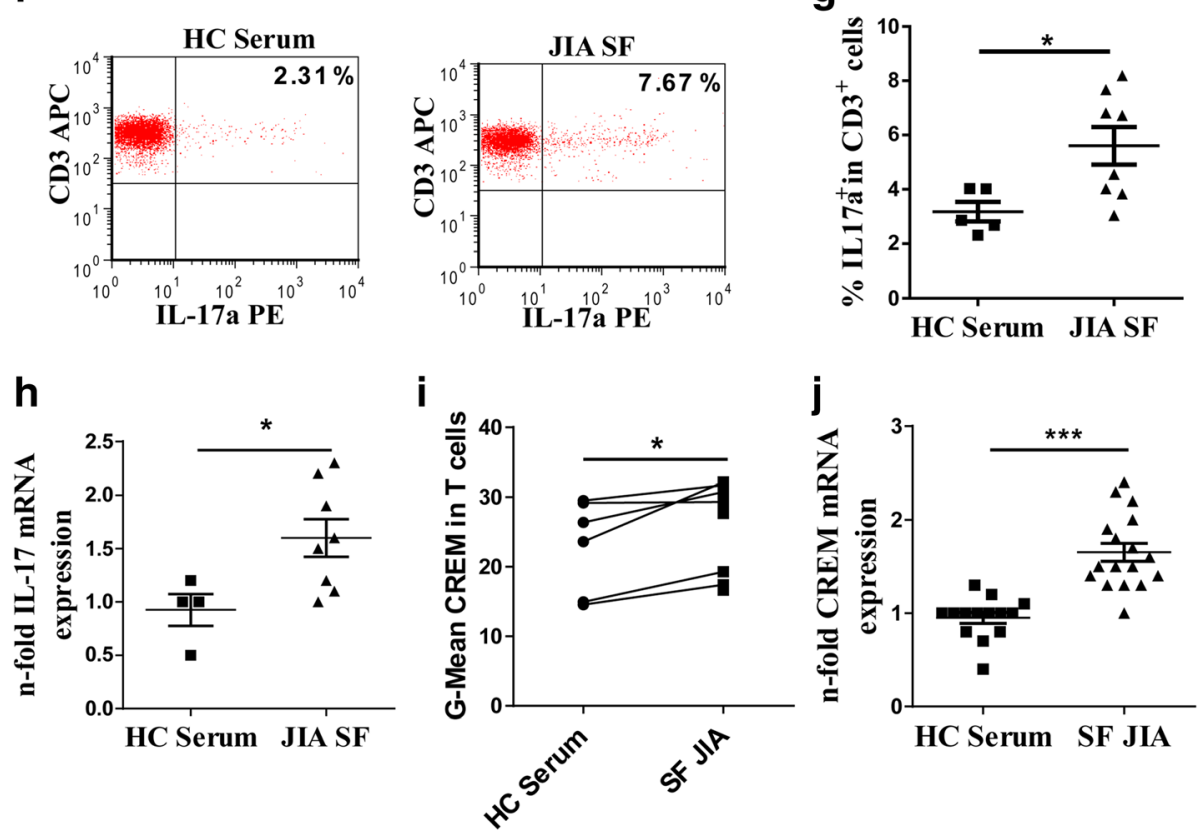

Fig. 1 CREM is overexpressed in JIA T cells. a Percentages of CREM high expressing T cells of 8 healthy control PBMCs and of 11 oligoarticular JIA SFMCs as assessed by flow cytometry. $\mathbf{b}$ Representative histogram showing mean fluorescent intensity of CREM expression in CD $3^{+} \mathrm{T}$ cells. $\mathbf{c}-\mathbf{j} \mathrm{HC}$ PBMCs were treated with 10\% SF or HC Serum in RPMl for $24 \mathrm{~h}$. c Percentages of Foxp3 ${ }^{+}$cells within $\mathrm{CD}^{+}{ }^{+} \mathrm{T}$ cells. $\mathbf{d}$ Representative dot plot of Foxp3 expressing T cells. e Foxp3 mRNA expression. f Representative dot plot of $\mathrm{IL}-17^{+}$expressing $\mathrm{T}$ cells after restimulation with $\mathrm{P} / \mathrm{I}$ in the presence of Brefeldin A. $\mathbf{g}$ Percentages of $\mathrm{IL}-17^{+}$cells within $C D 3^{+} \mathrm{T}$ cells after restimulation with $\mathrm{P} / \mathrm{I}$ in the presence of Brefeldin $\mathrm{A}$. $\mathbf{h} \mathrm{IL}-17 \mathrm{mRNA}$ expression. i Geometric (G)-Mean of CREM expression, paired, two tailed t-test. j CREM mRNA expression, two-tailed Mann Whitney test. Symbols present individual patients, SFs or HC sera and horizontal bars show SEM. A two-tailed unpaired t-test was used to calculate $p$-values in $\mathbf{a}, \mathbf{b}, \mathbf{e}, \mathbf{g}$ and $\mathbf{h}$

analysis revealed that siRNA knockdown results in reduced protein expression of CREM (Fig. 2a and b). We next incubated the cells with anti-CD3/CD28 antibodies. Our analysis showed that percentages of IL- $17 \mathrm{a}^{+}$, IFN- $\gamma^{+}$ and $\mathrm{FoxP}^{+}$cells were significantly reduced in CREM
siRNA transfected cells (Fig. 2c, d and e). To further analyze if CREM is required for IL-17a and FoxP3 expression under the inflammatory environment we stimulated $\mathrm{CD} 4^{+} \mathrm{T}$ cells with knocked down CREM by incubation in SF from JIA patients. Stimulation of $\mathrm{CD}^{+} \mathrm{T}$ cells with 

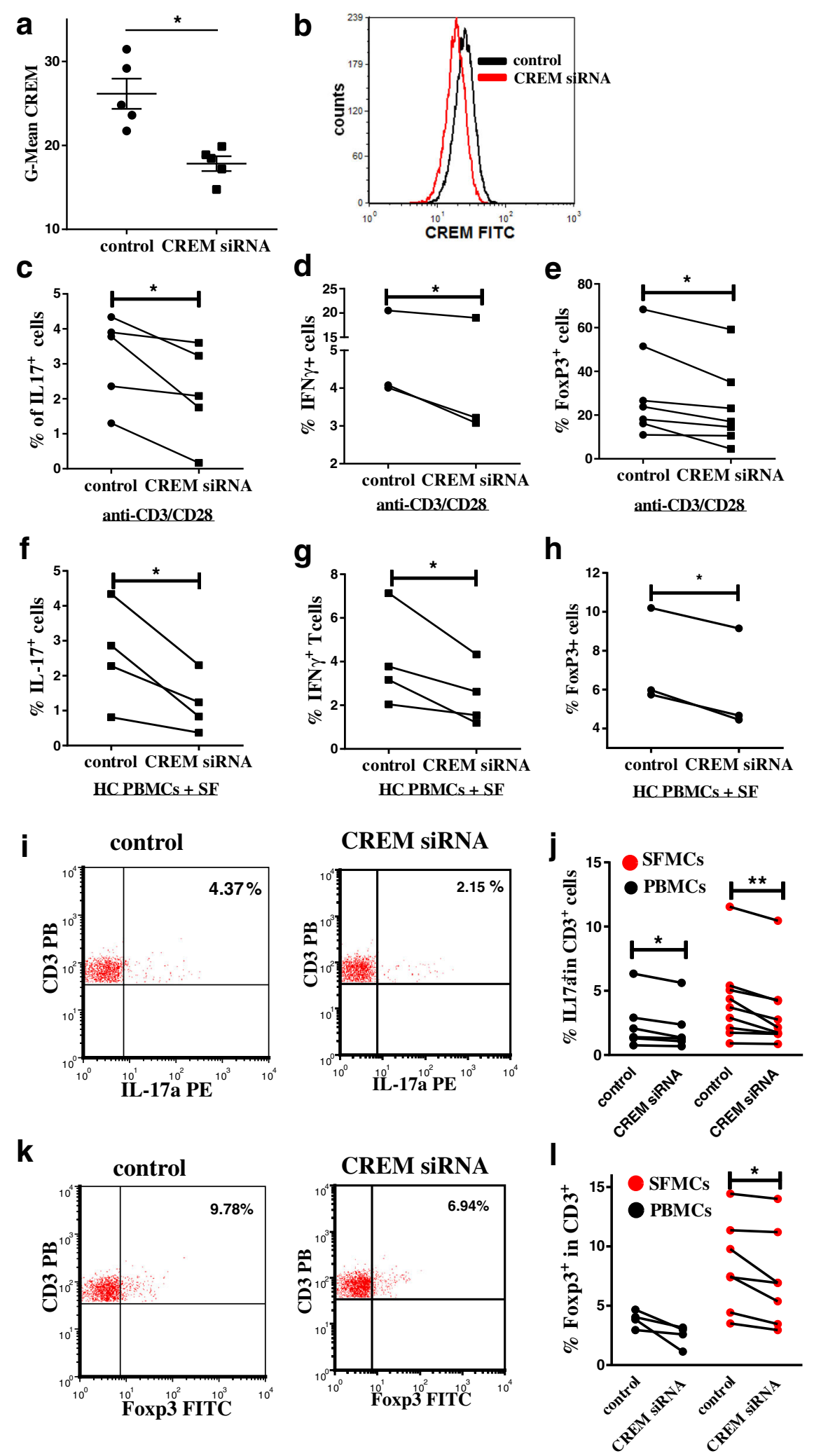

Fig. 2 (See legend on next page.) 


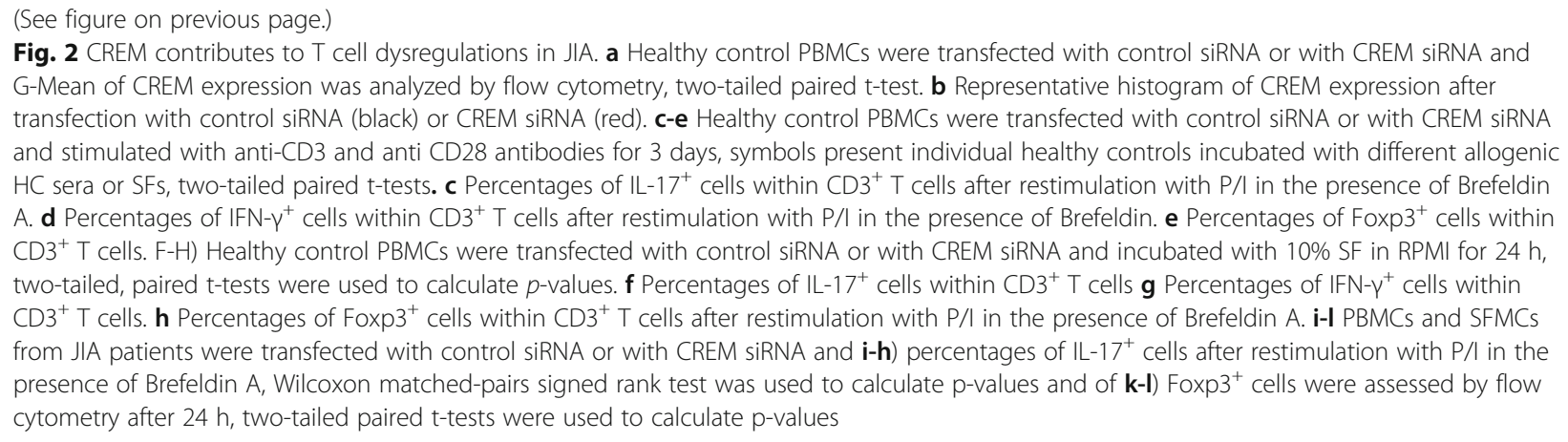

healthy control serum served as control. Similar to anti-CD3/CD28 antibody mediated stimulation of $\mathrm{CD} 4^{+} \mathrm{T}$ cells, also the SF-induced expression of IFN- $\gamma$, IL-17a and FoxP3 could be reversed in $\mathrm{CD} 4^{+} \mathrm{T}$ cells by expression of CREM-specific siRNA (Fig. 2f, g, and h). To establish the involvement of CREM $\alpha$ in the regulation of IL-17a, FoxP3 and IFN- $\gamma$ expression in JIA we transfected ex vivo isolated SFMC with either unrelated control siRNA or siRNA directed against CREM. SFMC transfected with CREM-specific siRNA expressed significantly lower percentages of FoxP3 ${ }^{+}$and $\mathrm{IL}_{17 \mathrm{a}^{+}}$cells (Fig. 2i-l). Hence, these experiments provide evidence for the involvement of CREM $\alpha$ in the regulation of IL-17 and FoxP3 expression in juvenile arthritic joints.

\section{CREM regulates inflammatory $\mathrm{CD} 161^{+} \mathrm{T}$ cells and determines the outcome in inflammatory arthritis} Among $\mathrm{CD}^{+}$cells the subset of $\mathrm{CD} 161^{+} \mathrm{T}$ cells are the most important in maintaining the inflammatory process and exactly this cell population is increased in the SF of JIA patients $[1,5]$. We thus analyzed the role of CREM $\alpha$ within this population of $\mathrm{CD}^{+}$cells. We found enhanced expression of CREM $\alpha$ in $\mathrm{CD} 161^{+} \mathrm{CD} 4^{+} \mathrm{PBMC}$ and of SFMC from JIA patients compared to their CD161 ${ }^{-}$counterparts (Fig. 3a). Treatment of HC PBMCs with SF upregulated $\mathrm{CD} 161^{+} \mathrm{CD} 4^{+} \mathrm{IL}-17^{+}$cells in the presence of CREM, while knock down of CREM inhibited the SF induced expression of this inflammatory subset (Fig. 3b). Unfortunately, in contrast to humans, mice do not express CD161 in cytokine-producing T cells and therefore we could not validate these data in vivo. Nevertheless, we performed a T cell dependent arthritis model in mice to analyze how CREM signaling in $\mathrm{T}$ cells influences the fate of an inflammatory arthritis.

To this end, we transferred $\mathrm{CD} 4^{+} \mathrm{CD} 25^{-} \mathrm{T}$ cells from either OTII-CREM ${ }^{-/-}$or control OTII-wild-type (WT) mice into $\mathrm{RAG}^{-1-}$ mice and immunized the mice with OVA to expand the T cells (Fig. 3c). On day 7 we induced arthritis by injecting cationic OVA-peptide into the right knee. As seen in Fig. 3d, transfer of CREM ${ }^{-/-}$ $\mathrm{T}$ cells resulted in a faster remission of arthritis and significantly lower histological scores for inflammation and tissue destruction (Fig. 3d-f).

\section{Discussion}

For the first time we provide evidence that CREM plays a role in $\mathrm{T}$ cell dysregulation in oligoarticular JIA patients. Our conclusion is based on several levels of evidence. First, we observed enhanced expression of CREM in SF T cells from JIA patients. Enhanced expression of CREM could also be induced after ex vivo culture of PBMCs from healthy donors with SF from JIA patients. CREM expression is also enhanced in SLE T cells and as well as SF Sera from SLE patients also induces CREM expression [26]. However, expression of CREM is regulated by complex mechanism and by at least two different promoter regions that are differentially activated in SLE and normal T cells [10]. Further studies will show which promoter regions are activated by SF. Second, we found enhanced expression of CREM in $\mathrm{CD} 4^{+} \mathrm{CD} 161^{+}$cells, which are known producers of inflammatory cytokines. Third, incubation with SF induced expression of IFN- $\gamma$, IL-17 and FoxP3 in T cells, which could be reversed by knock down of CREM. Finally deficiency of CREM in $\mathrm{T}$ cells ameliorated OVA induced arthritis in vivo.

There are some limitations to our study. While our data suggest that CREM directly regulates $\mathrm{CD} 4^{+} \mathrm{CD} 161^{+}$ $\mathrm{T}$ cells in human JIA, we cannot fully transfer this observation to our in vivo arthritis model as the murine analog of CD161 has not yet been identified. Furthermore, we could only analyze a small number of patients and further work is required to confirm our data.

Regarding the pathophysiology of JIA, the inflammatory reaction within the joint is initiated by cells of the innate immune system like neutrophils and macrophages, but cells of the adaptive immune system like B cells and $\mathrm{T}$ cells play a dominant role in perpetuating the disease. Pathogenic T cells within the joint display a mixed Th17/Th1 phenotype characterized by the production of IL-17 as well as IFN- $\gamma$ and expression of both lineage transcription factors $\mathrm{T}$-bet and RORyT [2]. 

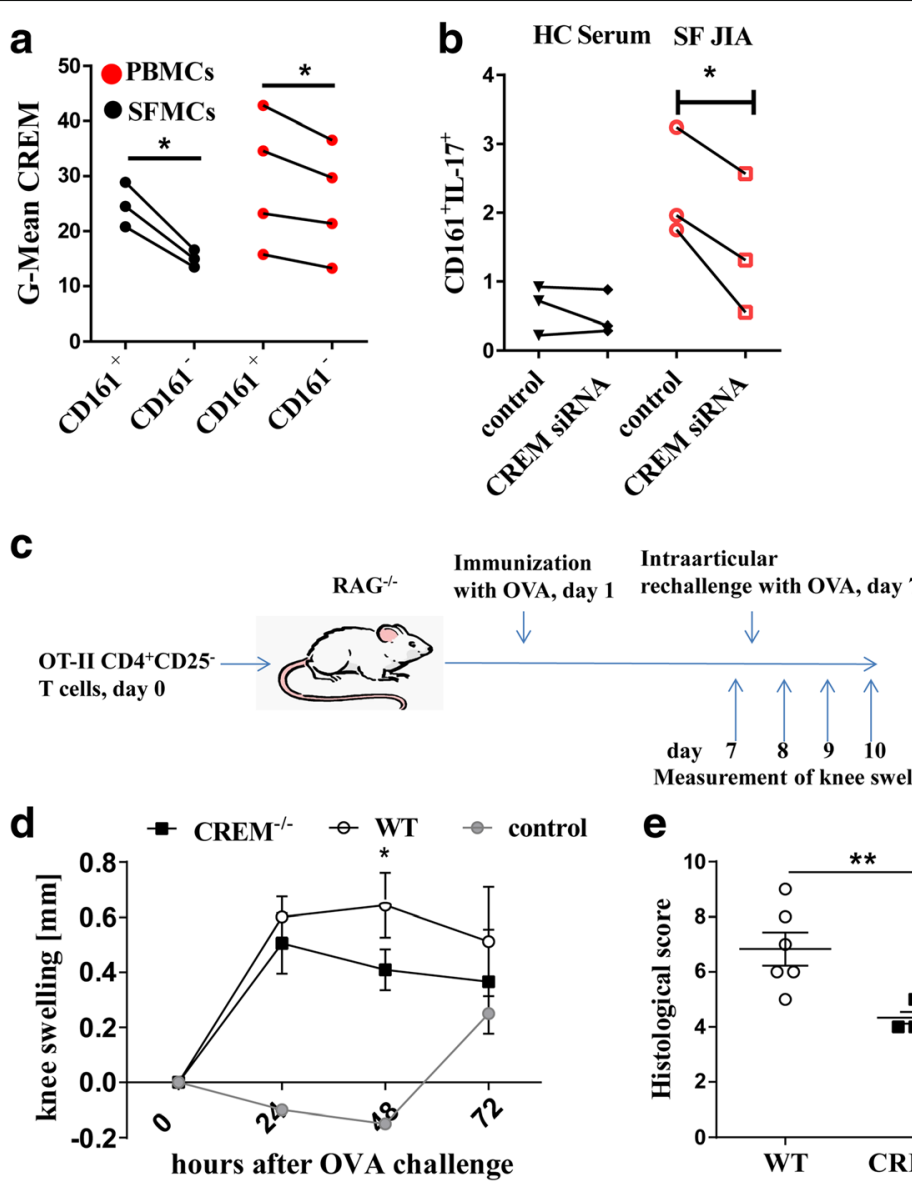

Intraarticular rechallenge with OVA, day 7

Measurement of knee swelling

e

$$
\text { f }
$$
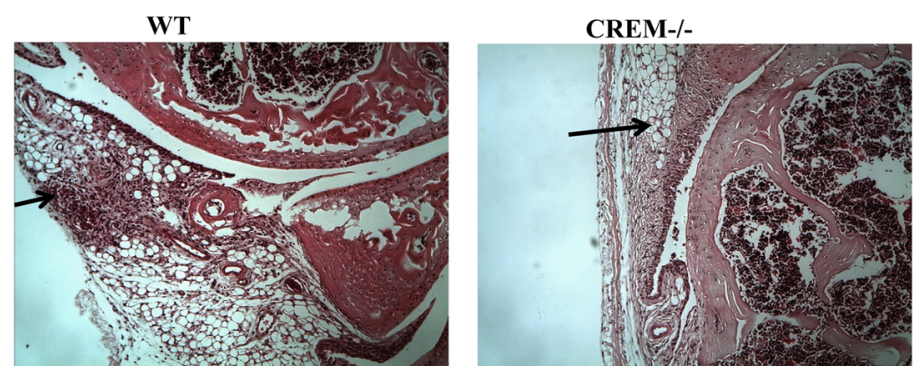

Fig. 3 CREM regulates T cell inflammation in arthritis. a Geometric (G)-Mean of CREM expression in PBMCs and SFMCs from JIA patients, two-tailed paired t-tests were used to calculate p-values. b PBMCs and SFMCs from JIA patients were transfected with control siRNA or with CREM siRNA and cultivated in RPMI for $24 \mathrm{~h}$ and percentages of $\mathrm{CD} 161^{+} \mathrm{IL}-17^{+}$in $\mathrm{CD}^{+} \mathrm{T}$ cells after restimulation with $\mathrm{P} / \mathrm{I}$ in the presence of Brefeldin were determined, two-tailed paired t-tests were used to calculate p-values. c Graphic showing T cell mediated arthritis model. d Knee swelling of $\mathrm{RAG}^{-1-}$ mice after adoptive transfer of OT-Il cells either from WT or from $\mathrm{CREM}^{-1-}$ mice, immunization with OVA and subsequent intraarticular injection of cationic ovalbumin. e Histological scores of arthritis-induced knee joints, Mann Whitney test were used to calculate $p$-values. $\mathbf{f}$ Hematoxylin and eosin staining of knee joint sections (arrow on the loft shows cellular infiltration, arrow on the right shows thickening of the synovial membrane)

Furthermore, in humans, these cells display a high expression of CD161, low expression of the TCR $\zeta$ chain (CD247) and low expression of IL-2 as well as low response to stimulation with IL-2 [27]. In addition, the TCR $\zeta$ chain has been established recently as an independent risk factor for JIA in linkage analysis studies [28]. The same is true for the IL2- receptor [29].
Interestingly, despite abundance of pathogenic $\mathrm{T}$ cells within the inflamed joint, the expression of detectable IL-2 within the joint is negligible [30]. This could be the result of decreased expression of IL-2 by the Th17 cells [27] or of consumption by the abundant regulatory $\mathrm{T}$ cells, which are dependent on IL-2. CREM $\alpha$ has been shown before to downregulate the TCR $\zeta$ chain and the 
IL-2 expression in SLE while enhancing secretion of IL-17 and IL-21 [12, 13, 16, 20, 31] and as shown here also dysregulates $\mathrm{T}$ cell responses in JIA as shown by our siRNA and in vivo studies. We therefore suggest that CREM regulates $\mathrm{T}$ cells in JIA by several mechanisms, which similarly to consequences of CREM overexpression in SLE contributes to an aberrant cytokine-expression profile and an enhanced occurrence of Th17 cells. How exactly CREM is activated in the synovium remains to be elucidated.

Recent studies underline the importance of a balance between inflammatory $\mathrm{T}$ cells and Tregs within inflamed joints [32] and CREM mediated mechanism might have potential as a therapeutic strategy for Th17-driven autoimmune diseases. It is therefore noticeable that genetic or pharmacologic inhibition of calcium/calmodulin-dependent protein kinase IV (CaMK4) reduced Il-17 transcription through decreased activation of CREM $\alpha$ [21]. Furthermore a recent clinical trial demonstrated the safety and efficacy of low-dose IL-2 treatment on SLE [33]. This shows that there are already advances to re-establish CREM-mediated dysregulations in T cells in autoimmune diseases and our study suggests that it would be valuable to further analyze the therapeutic potential of these mechanisms in JIA as well.

\section{Conclusion}

$\mathrm{T}$ cell dysregulations critically contribute to ongoing inflammation in juvenile arthritis joints. By identifying CREM as a transcriptional activator that contributes to increased occurrence of inflammatory effector $\mathrm{T}$ cells within the joints; our study puts CREM $\alpha$ in a central role within JIA and makes it a possible attractive target for pharmacological intervention.

\section{Abbreviations \\ CREM: CAMP responsive element modulator; HC: Healthy control; JIA: Juvenile idiopathic arthritis; OVA: Ovalbumin; PB: Peripheral blood; PBMC: Peripheral blood mononuclear cells; SF: Synovial fluid}

\section{Funding}

HM was supported in part by National Institutes of Health Grant Award Numbers: National Institute of Arthritis and Musculoskeletal and Skin Diseases P30 AR070549, Eunice Kennedy Shriver National Institute of Child Health and Human Development R01 HD089928, National Institute of Allergy and Infectious Diseases (NIAID) U01 Al130830. The content is solely the responsibility of the authors and does not necessarily represent the official views of the National Institutes of Health. LW is supported by the NIHR Biomedical Research Centre at Great Ormond Street Hospital for Children NHS Foundation Trust; HM and LW were supported by grants from SPARKS UK reference $08 \mathrm{I} \mathrm{CH} 09$.

The study was supported by a grant of the Novartis foundation.

\section{Availability of data and materials}

The datasets used and/or analysed during the current study are available from the corresponding author on reasonable request.

\section{Authors' contributions}

All authors were involved in drafting the article or revising it critically for important intellectual content, and all authors approved the final version to be published. Dr. T had full access to all of the data in the study and takes responsibility for the integrity of the data and the accuracy of the data analysis. KO, HN, HM, PK and AS contributed to the acquisition of data, analysis and interpretation of data. WW, DF and LW contributed to the acquisition of samples, contributed to study design and provided critical feedback on intellectual content. KT conceived the study and wrote the paper.

\section{Ethics approval and consent to participate}

The use of human samples was approved by the local ethics committee (Ethics Committee RWTH Aachen, Faculty of Medicine; EK228/15). All patients had given informed written consent to participate in the study. Experiments involoving animal were approved by the regional government authorities and animal procedures were performed according to German legislation for animal protection.

\section{Consent for publication}

All authors approved the final version to be published. The manuscript does not contain data from any individual person.

\section{Competing interests}

The authors declare that they have no competing interests.

\section{Publisher's Note}

Springer Nature remains neutral with regard to jurisdictional claims in published maps and institutional affiliations.

\section{Author details}

${ }^{1}$ Department of Pediatrics, Medical Faculty, RWTH Aachen, Pauwelsstr. 30, D-52074 Aachen, Germany. ${ }^{2}$ Center for Autoimmune Genomics \& Etiology, Cincinnati Children's Hospital Medical Center, Cincinnati, OH, USA. ${ }^{3}$ Department of Pediatrics, University of Cincinnati, College of Medicine, Cincinnati, OH, USA. ${ }^{4}$ Department of Pediatric Rheumatology and Immunology, University Hospital Muenster, Muenster, Germany. ${ }^{5}$ Institute of Virology, Westfaelische Wilhelms University, 48149 Muenster, Germany. ${ }^{6}$ Arthritis Research UK Centre for Adolescent Rheumatology at UCL UCLH and GOSH, London, UK. ${ }^{7}$ UCL GOS Institute of Child Health, University College London, London, UK. ${ }^{8} \mathrm{NIHR}$ - Great Ormond Street Hospital Biomedical Research Centre (BRC), London, UK.

Received: 19 March 2018 Accepted: 6 June 2018

Published online: 20 June 2018

\section{References}

1. Nistala K, Adams S, Cambrook H, Ursu S, Olivito B, de Jager W, et al. Th17 plasticity in human autoimmune arthritis is driven by the inflammatory environment. Proc Natl Acad Sci U S A. 2010;107(33):14751-6.

2. Pesenacker AM, Bending D, Ursu S, Wu Q, Nistala K, Wedderburn LR. CD161 defines the subset of FoxP3+ T cells capable of producing proinflammatory cytokines. Blood. 2013;121(14):2647-58.

3. Duurland CL, Brown CC, O'Shaughnessy RF, Wedderburn LR. CD161(+) Tconv and CD161(+) Treg share a transcriptional and functional phenotype despite limited overlap in TCRbeta repertoire. Front Immunol. 2017:8:103.

4. Cosmi L, De Palma R, Santarlasci V, Maggi L, Capone M, Frosali F, et al. Human interleukin 17-producing cells originate from a CD161+CD4+ T cell precursor. J Exp Med. 2008;205(8):1903-16.

5. Cosmi L, Cimaz R, Maggi L, Santarlasci V, Capone M, Borriello F, et al. Evidence of the transient nature of the Th17 phenotype of CD4+CD161+ T cells in the synovial fluid of patients with juvenile idiopathic arthritis. Arthritis Rheum. 2011;63(8):2504-15.

6. Kryczek I, Wu K, Zhao E, Wei S, Vatan L, Szeliga W, et al. IL-17+ regulatory T cells in the microenvironments of chronic inflammation and cancer. J Immunol. 2011;186(7):4388-95.

7. Dominguez-Villar M, Baecher-Allan CM, Hafler DA. Identification of T helper type 1-like, Foxp3+ regulatory $T$ cells in human autoimmune disease. Nat Med. 2011;17(6):673-5.

8. Beriou G, Costantino CM, Ashley CW, Yang L, Kuchroo VK, Baecher-Allan C, et al. IL-17-producing human peripheral regulatory $T$ cells retain suppressive function. Blood. 2009;113(18):4240-9.

9. Afzali B, Mitchell PJ, Edozie FC, Povoleri GA, Dowson SE, Demandt L, et al. CD161 expression characterizes a subpopulation of human regulatory $T$ 
cells that produces IL-17 in a STAT3-dependent manner. Eur J Immunol. 2013;43(8):2043-54.

10. Rauen T, Benedyk K, Juang YT, Kerkhoff C, Kyttaris VC, Roth J, et al. A novel intronic CAMP response element modulator (CREM) promoter is regulated by activator protein-1 (AP-1) and accounts for altered activation-induced CREM expression in T cells from patients with systemic lupus erythematosus. J Biol Chem. 2011;286(37):32366-72.

11. Rauen T, Hedrich CM, Tenbrock K, Tsokos GC. CAMP responsive element modulator: a critical regulator of cytokine production. Trends Mol Med. 2013:19(4):262-9.

12. Tenbrock K, Juang YT, Tolnay M, Tsokos GC. The cyclic adenosine 5'monophosphate response element modulator suppresses IL-2 production in stimulated T cells by a chromatin-dependent mechanism. J Immunol. 2003;170(6):2971-6.

13. Tenbrock K, Kyttaris VC, Ahlmann M, Ehrchen JM, Tolnay M, Melkonyan H, et al. The cyclic AMP response element modulator regulates transcription of the TCR zeta-chain. J Immunol. 2005;175(9):5975-80.

14. Tenbrock K, Juang YT, Gourley MF, Nambiar MP, Tsokos GC. Antisense cyclic adenosine 5 '-monophosphate response element modulator up-regulates IL2 in T cells from patients with systemic lupus erythematosus. J Immunol. 2002;169(8):4147-52.

15. Rauen T, Hedrich CM, Juang YT, Tenbrock K, Tsokos GC. CAMP-responsive element modulator (CREM)alpha protein induces interleukin 17A expression and mediates epigenetic alterations at the interleukin-17A gene locus in patients with systemic lupus erythematosus. J Biol Chem. 2011;286(50): 43437-46.

16. Lippe R, Ohl K, Varga G, Rauen T, Crispin JC, Juang YT, et al. CREMalpha overexpression decreases IL-2 production, induces a $\mathrm{T}(\mathrm{H}) 17$ phenotype and accelerates autoimmunity. J Mol Cell Biol. 2012;4(2):121-3.

17. Ohl K, Wiener A, Schippers A, Wagner N, Tenbrock K. IL-2 treatment reverses effects of CREMalpha-overexpressing $T$ cells in autoimmune-prone mice. Clin Exp Immunol. 2015;181(1):76-86.

18. Verjans E, Ohl K, Yu Y, Lippe R, Schippers A, Wiener A, et al. Overexpression of CREMalpha in T cells aggravates lipopolysaccharide-induced acute lung injury. J Immunol. 2013;191(3):1316-23.

19. Verjans $E$, Ohl K Reiss LK, van Wijk F, Toncheva AA, Wiener $A$, et al. The CAMP response element modulator (CREM) regulates TH2 mediated inflammation. Oncotarget. 2015;6(36):38538-51.

20. Ohl K, Wiener A, Lippe R, Schippers A, Zorn C, Roth J, et al. CREM alpha enhances IL-21 production in T cells in vivo and in vitro. Front Immunol. 2016;7:618.

21. Koga T, Hedrich CM, Mizui M, Yoshida N, Otomo K, Lieberman LA, et al. CaMK4-dependent activation of AKT/mTOR and CREM-alpha underlies autoimmunity-associated Th17 imbalance. J Clin Invest. 2014;124(5):2234-45.

22. Stittrich AB, Haftmann C, Sgouroudis E, Kuhl AA, Hegazy AN, Panse I, et al. The microRNA miR-182 is induced by IL-2 and promotes clonal expansion of activated helper T lymphocytes. Nat Immunol. 2010;11(11):1057-62.

23. Blendy JA, Kaestner KH, Weinbauer GF, Nieschlag E, Schutz G. Severe impairment of spermatogenesis in mice lacking the CREM gene. Nature. 1996;380(6570):162-5.

24. Nistala $K$, Moncrieffe $H$, Newton KR, Varsani $H$, Hunter $P$, Wedderburn LR. Interleukin-17-producing $T$ cells are enriched in the joints of children with arthritis, but have a reciprocal relationship to regulatory $T$ cell numbers. Arthritis Rheum. 2008;58(3):875-87.

25. de Kleer IM, Wedderburn $L R$, Taams $L S$, Patel A, Varsani $H$, Klein $M$, et al. CD4+CD25bright regulatory $T$ cells actively regulate inflammation in the joints of patients with the remitting form of juvenile idiopathic arthritis. J Immunol. 2004;172(10):6435-43.

26. Juang YT, Wang Y, Solomou EE, Li Y, Mawrin C, Tenbrock K, et al. Systemic lupus erythematosus serum IgG increases CREM binding to the IL-2 promoter and suppresses IL-2 production through CaMKIV. J Clin Invest. 2005;115(4):996-1005.

27. Santarlasci V, Maggi L, Capone M, Querci V, Beltrame L, Cavalieri D, et al. Rarity of human $\mathrm{T}$ helper 17 cells is due to retinoic acid orphan receptor-dependent mechanisms that limit their expansion. Immunity. 2012;36(2):201-14

28. Hinks A, Cobb J, Sudman M, Eyre S, Martin P, Flynn E, et al. Investigation of rheumatoid arthritis susceptibility loci in juvenile idiopathic arthritis confirms high degree of overlap. Ann Rheum Dis. 2012;71(7):1117-21.

29. Hinks A, Ke X, Barton A, Eyre S, Bowes J, Worthington J, et al. Association of the IL2RA/CD25 gene with juvenile idiopathic arthritis. Arthritis Rheum. 2009;60(1):251-7.
30. Lepore L, Pennesi M, Saletta S, Perticarari S, Presani G, Prodan M. Study of IL-2, IL-6, TNF alpha, IFN gamma and beta in the serum and synovial fluid of patients with juvenile chronic arthritis. Clin Exp Rheumatol. 1994;12(5):561-5.

31. Ohl K, Wiener A, Schippers A, Wagner N, Tenbrock K. Interleukin-2 treatment reverses effects of CAMP-responsive element modulator alpha-overexpressing T cells in autoimmune-prone mice. Clin Exp Immunol. 2015; 181(1):76-86.

32. Maggi L, Cosmi L, Simonini G, Annunziato F, Cimaz R. T cell subpopulations in juvenile idiopathic arthritis and their modifications after biotherapies. Autoimmun Rev. 2016;15(12):1141-4.

33. von Spee-Mayer C, Siegert E, Abdirama D, Rose A, Klaus A, Alexander T, et al. Low-dose interleukin-2 selectively corrects regulatory $T$ cell defects in patients with systemic lupus erythematosus. Ann Rheum Dis. 2016;75(7): 1407-15.

\section{Ready to submit your research? Choose BMC and benefit from:}

- fast, convenient online submission

- thorough peer review by experienced researchers in your field

- rapid publication on acceptance

- support for research data, including large and complex data types

- gold Open Access which fosters wider collaboration and increased citations

- maximum visibility for your research: over $100 \mathrm{M}$ website views per year

At BMC, research is always in progress.

Learn more biomedcentral.com/submissions 